\title{
Increase in energy efficiency of a system a car wheel - a paving
}

\author{
Stanislav Gorin ${ }^{1}$, Sergey Vyalov ${ }^{1}$, Pavel Kharlamov ${ }^{1}$, Oleg Meleshko ${ }^{1}$, and \\ Sergey Nosachev ${ }^{2}$ \\ ${ }^{1}$ Rostov State Transport University, 344038 Rostovskogo Strelkovogo Polka Narodnogo Opolcheniya \\ Sq. 2, Rostov-on-Don, Russia \\ ${ }^{2}$ Don State Technical University, 344000 Rostov-on-Don, Russia
}

\begin{abstract}
One of the negative effects arising in the course of operation of a vehicle wheel is out-of-balance condition. Disbalance of a car wheel can be caused by various reasons, including change in geometrical form of the rim, violation of norms of operation, non-optimal position of the tire in relation to the rim. Change of geometry is caused by operation of the rim, casual reasons, as well as influence of external conditions of work and rim storage. Latent faults, construction overload, etc. belong to casual reasons. Results of the experiments fulfilled show that in most cases violation of the geometrical form of a rim, which sometimes cannot be defined by eye is the reason of increase in disbalance of a wheel. A stand for control of geometry of rim and a device allowing to perform "optimization" of car wheels on the basis of mathematical model of process of optimization of tire position in relation to the rim in the conditions of dynamic balancing of wheels have been developed.
\end{abstract}

\section{Introduction}

One of the negative effects arising in the course of operation of a vehicle wheel is out-ofbalance condition. Disbalance of a car wheel can be caused by various reasons, including change in geometrical form of the rim, violation of norms of operation, non-optimal position of the tire in relation to the rim. Change of geometry is caused by operation of the rim, casual reasons, as well as influence of external conditions of work and rim storage. Latent faults, construction overload, etc. belong to the casual reasons. The principal permanent reasons for change of technical condition of parts and the automobile in general are wear, plastic deformation, fatigue failures, corrosion, physical and chemical changes in material of components. During the operation of a wheel rim value of design and diagnostic data change ranging from initial values to the admissible, and then extreme values which are regulated by state standard specifications.

Present day tire repair shops willingly carry out balancing of wheels, but quite often the weight of the correcting loads doesn't meet the requirements of GOST [1], and mechanics inevitably discard a wheel without considering the reasons. Results of the experiments fulfilled show that in most cases distortion of the geometrical form of a rim, which sometimes cannot be defined by eye is the reason of increase in disbalance of a wheel. 
In the course of operation of an automobile wheel a tire wears out much quicker than a rim therefore the most common case is installation of a new tire on a rim, which has already been in operation. The above examples of pilot study of rims confirm change of their geometry in the process of operation that in its turn leads to increase in weight of the correcting loads in the conditions of dynamic balancing of a wheel.

Quality of balancing is influenced by position of a tire in relation to a wheel rim [2]. The existing balancing machines often fail to carry out optimization of position of a tire in relation to a rim that not to the best affects quality of balancing, increasing the weight of the correcting loads.

\section{Methods}

A stand for controlling the geometry of wheel rims (Fig. 1) has been designed to control the geometry of the contact surface and mounting surface of automobile rim.
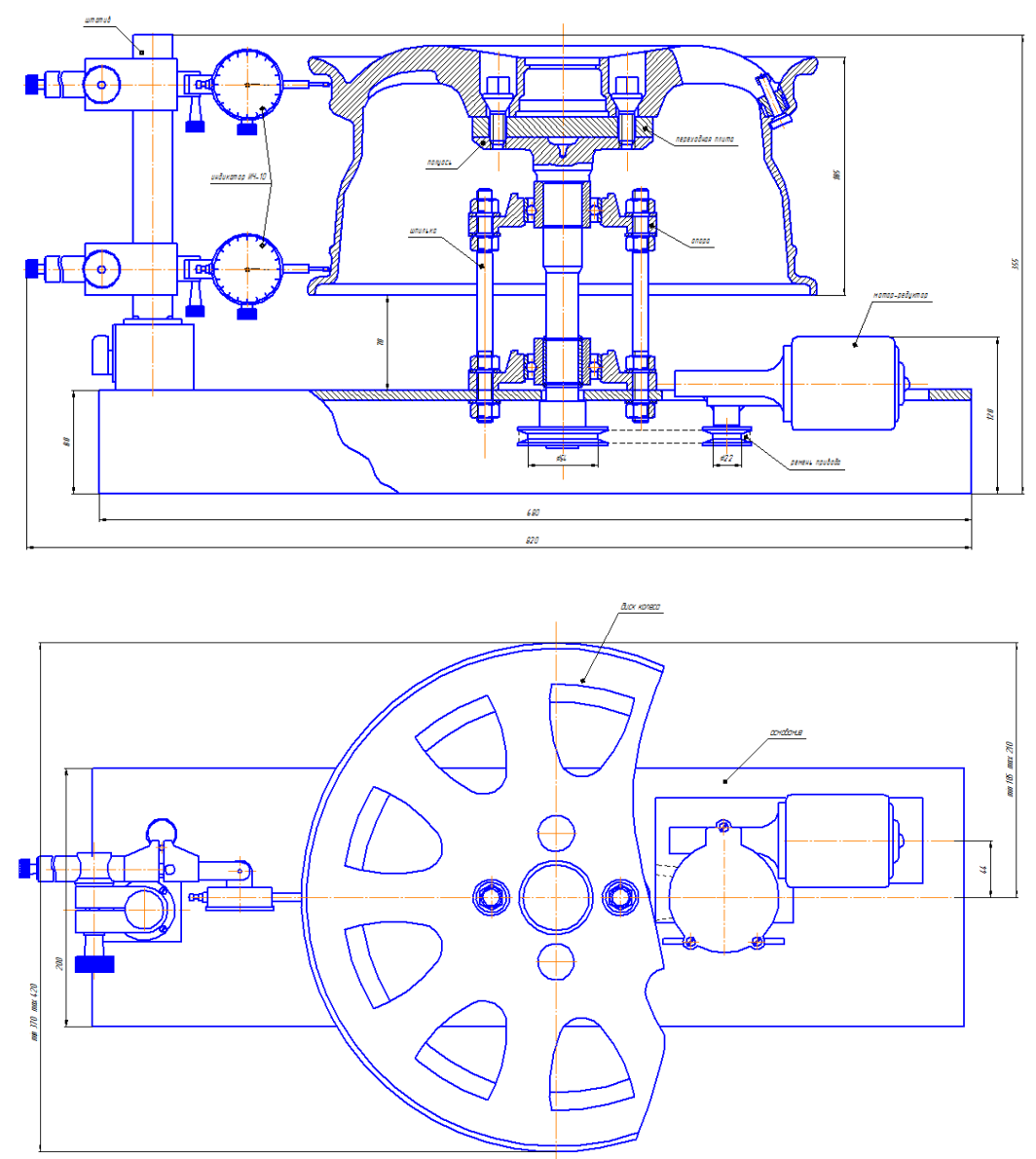

Fig. 1. Stand general view.

Its principal characteristics are: diameter of the measured rim is $12 "-16 "$, design capacity is 4 wheel/hour, $12 \mathrm{~V}$ power supply, protection against electric shock - class "I", overall dimensions $-820 \times 370 \times 355 \mathrm{~mm}$, weight $-22 \mathrm{~kg}$. It is also supplied with universal adapter plate for fastening the disk, built-in case to store accessories and tools, pointer of the beat on 
movable rod. Structurally stand for geometry control is in fact a set of subassemblies and units, mounted according to functional links on the metal base to ensure stability of the stand as a whole. The stand is equipped with an electric drive with gear motor, the torque is transmitted from the output shaft of the gearbox to the shaft of the stand and through the adapter plate, directly onto the rim itself. Rim is mounted on the adapter plate with the help of centering washers and special fastening screws included in the package of the stand. Control of rim geometry is carried out by rotation of a shaft of the stand with the help of the geared motor; the torque transmission from gear motor to the shaft of the stand is accomplished through a belt drive. Unlike known counterparts, the measurement system design uses several measurement indicators that can measure multiple planes making the measuring process more rapid. The stand structure uses positioning posts that impart greater rigidity to the stand structure, a more accurate positioning and ease of assembly.

Positioning posts are secured to the base with the help of guide pins.

As a system for installation of measuring heads the mount for measuring heads of ШMIIH No.09315 type of first class of accuracy is used. A device has been developed (fig. 2) allowing on the basis of mathematical model of the process of optimization of tire position in relation to wheel rim in the conditions of dynamic balancing of wheels to perform "optimization" of automobile wheels in the conditions of ordinary tire repair shops on the basis of the available balancing machines. The device can be exploited in the conditions of tire repair shops.

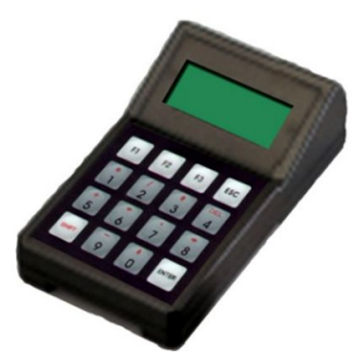

Fig. 2. Device outside appearance.

Key assignment of the keypad:

F1 - Button of input of basic data. Use this button to start calculation.

F2 - Calculation button. By means of this button calculation for the preset values is carried out.

F3 - Result button. Gets the result of calculations displayed.

ESC - Canceling button. Allows to cancel the current operation or to quit the current mode.

$1 \ldots 0$ - the Number pad. Serves for input of numbers. By means of it values of basic data are entered.

SHIFT - switches the color of buttons.

ENTER - Input button. Confirms the entered value of data for calculation.

DEL - Deleting button. Serves for deleting the character positioned over the cursor.

$\downarrow \uparrow-$ navigation Buttons. By means of these buttons scrolling of the list of the preset values in the course of data entry, and the list of result of computation is possible.

Basis for the development of the method is the mathematical model [3] allowing to subdivide a wheel disbalance into the disbalance of tire and the disbalance of rim. This subdivision can be made according to the information on disbalance of a wheel received from indicators of the balancing machine. 
Information from the balancing machine is transferred to the computing device, which defines the optimum side of the tire and the optimum angle of turn of the tire in relation to the rim according to the calculated and saved information on the disbalance of the tire and the rim.

\section{Results}

The proposed stand allows to control the geometry of the forms of rims of different design. Figures 3 and 4 show the control data and the geometry of the the contact surface and mounting surface of stamped and molded wheel rims of $6,5 \mathrm{Jx} 13 \mathrm{H} 2$ size.
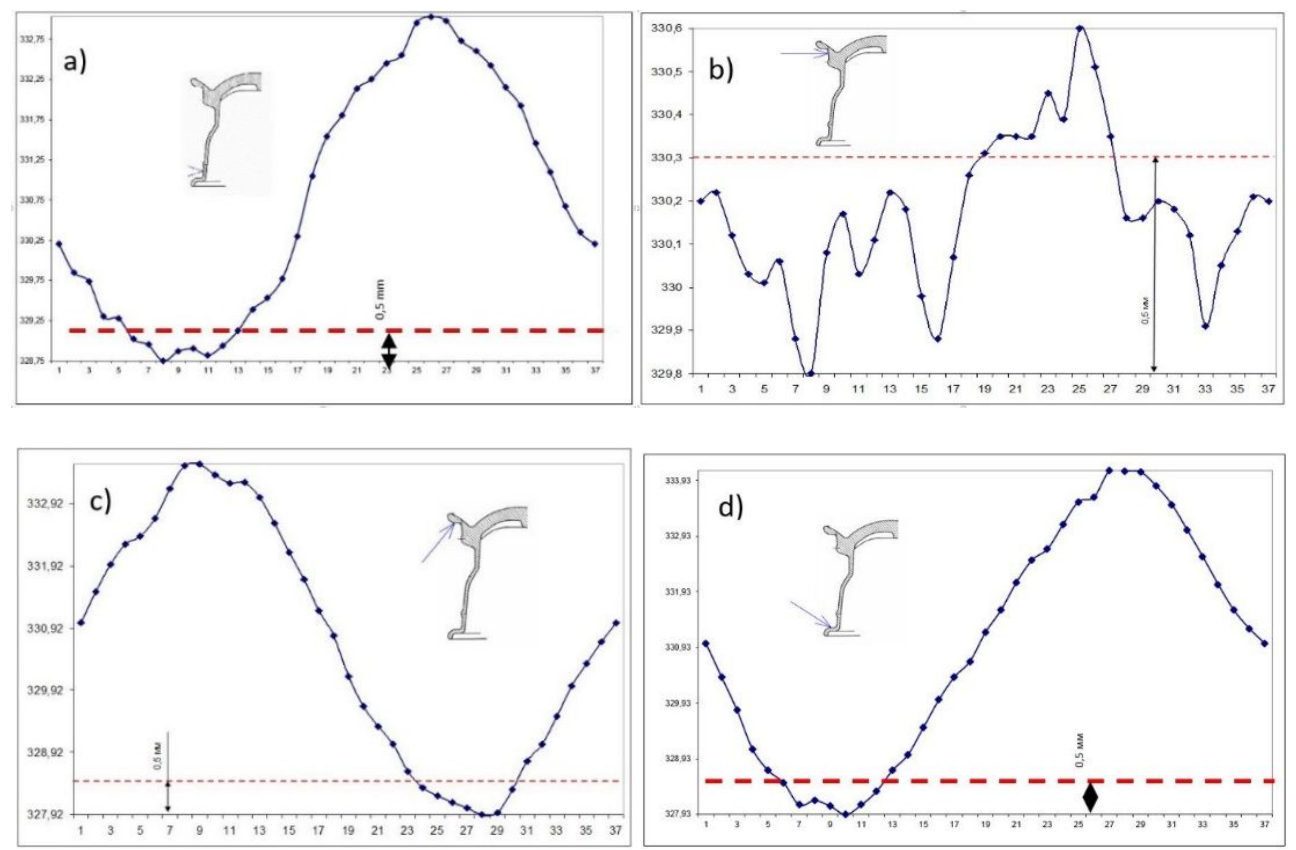

Fig. 3. Deviations in geometry of stamped rim surfaces ( size $-6,5 \mathrm{Jx} 13 \mathrm{H} 2$,service life - 75 thousand $\mathrm{km})$ : $\mathrm{a}$ - inside contact surface, $\mathrm{b}$ - outside contact surface, $\mathrm{c}$ - outside mounting surface, $\mathrm{d}$ - inside mounting surface 


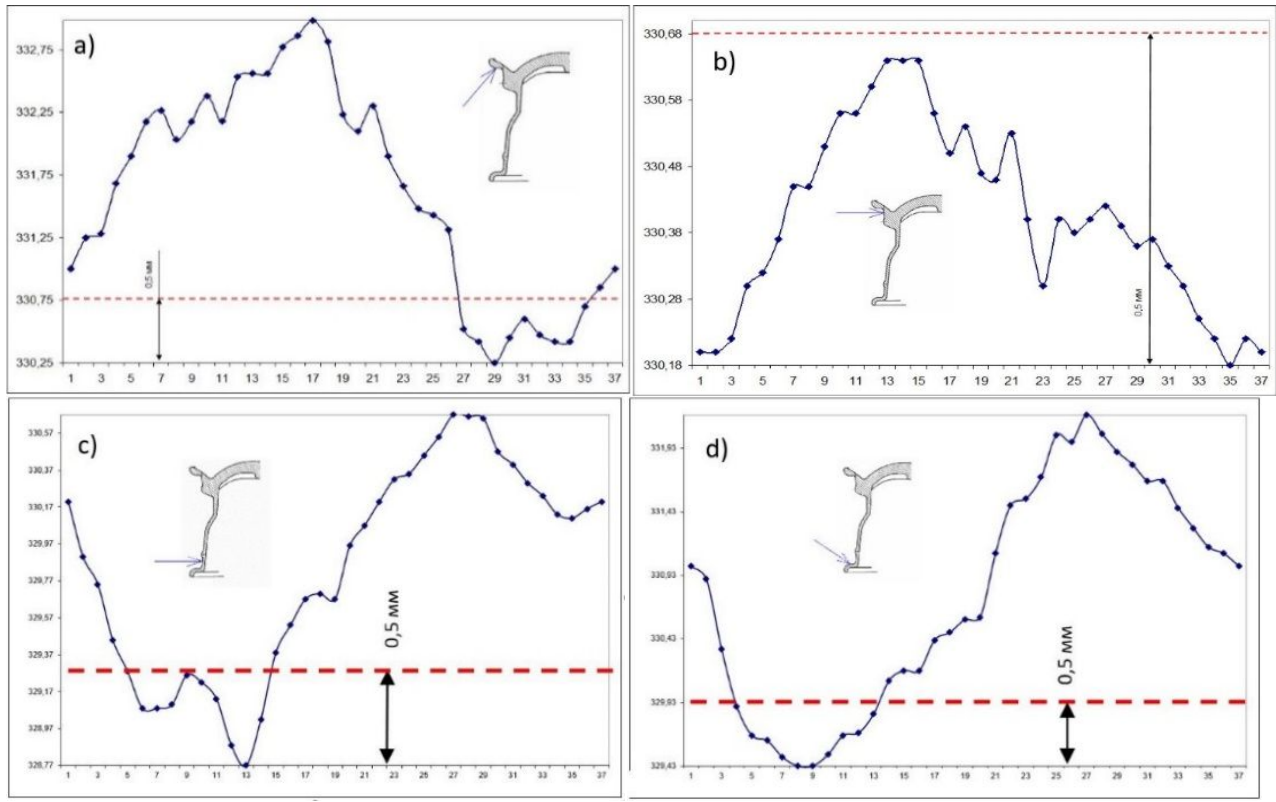

Fig. 4. Deviations in geometry of cast rim surfaces (size- 6,5 Jx13H2, service life - 72 thousand $\mathrm{km}$ ): a - inside contact surface, $b$ - outside contact surface, $c$ - outside mounting surface, $d$-inside mounting surface.

The dashed line indicates normable GOST size deviation of $0.5 \mathrm{~mm}$. Selected rims visually have no trace of distortion. Analysis of the relationship shows that the deviation of the measured geometry of the molded disk surfaces is much less extruded at similar values of life (about $75000 \mathrm{Km}$.). Ovality of contact surfaces is more pronounced in both cases in the inner disk plane, which may be caused by insufficient rigidity of the rim. Change of geometry of the mounting surfaces is more observed in stamped rims. This may be as well due to the lack of rigidity, as this is the place where the impact of squeezing blades of tire changer when changing tire is applied.

The provided complex allows to determine more precisely the defects of a wheel influencing dynamic balancing, to prolong service life, both of the rim and the wheel in general, to reduce the weight of the correcting loads and to increase energy efficiency of a system a car wheel - a paving.

Researches are conducted within realization of a grant of JSC «Russian Railways» on development of scientific and pedagogical schools in the field of railway transport.

\section{References}

1. GOST 4754-97. Pneumatic tires for automobiles, automobile trailers, passenger trucks and buses of especially small capacity. Specifications (2018)

2. S.L. Gorin, P.V. Kharlamov, Bulletin of the RSTU, 1(41), 12 (2011)

3. S.L. Gorin, V.G. Sapronov, V.G. Fetisov Mathematical modeling of technological processes in automobile service (monograph) (Publishing house of SRSUES, Shakhty, 2009)

4. GOST P - 50511 - 93. Wheels from light alloys for pneumatic tires. General specifications. 
5. V.V. Shapovalov, P.V. Kharlamov, S.L. Gorin, Proceedings of the tenth anniversary AllRussia scientific and technical conference with participation of foreign experts, 145 (2014).

6. Y.vYang, S. Chu, W. Chang, and T. Wu, EOH, Int. Commun. Heat Mass Tran., 6, 37 (2010).

7. M. Dumitriu, MOR. Applied Mechanics and Materials. 4, 371 (2013).

8. A. Loktev, E. Gridasova, E. Zapolnova SOT Part 1. RMF. Contemporary Engineering Sciences.9, 8 (18) (2015).

9. V. Shapovalov., A. Lubyagov, P. Kharlamov AOT , Transport Problems, 10, 12 (2017). 